\title{
THE ROLE OF UNIVERSAL SPORTS SCHOOL IN SPORTS SELECTION
}

\author{
Dino Siber \\ Football Club Osijek \\ Mihael Horvatek \\ Universal Sports School, Našice
}

\begin{abstract}
The Universal Sports School (hereinafter USŠ) is a project of the Croatian School Sports Federation (hereinafter HŠSS) carried out in lower grades of primary education in the Republic of Croatia. The project involves children from $1^{\text {st }}$ to $4^{\text {th }}$ grade of primary schools and it is conducted by both P.E. teachers and kinesiologists. The aim of the project is to encourage the multifaceted psychosomatic development of children, to raise awareness of preserving and improving health, doing daily physical exercise and to develop motor and functional abilities. The paper focuses on sports selection as a method for identifying potential top athletes and on the notion of USŠ, which is a HŠSS project, regarded as a system for carrying out a selection and directing of potential young athletes for the sports in which they can achieve optimal results in their future sports activities.
\end{abstract}

Keywords: selection in sports, Universal Sports School, sports specialization

\section{INTRODUCTION}

The main goal of USŠ is to encourage a multifaceted psychosomatic development of children, to build a culture of health in order to preserve and improve health of an individual and healthy environment, to meet children's needs for movement and exercise as well as to acquire a habit of regular sporting practice and exercise (Škegro et al., 2007). The USŠ project was launched in 2007 and has been implemented by HŠSS. It has been implemented at the national level and it has recorded a steady increase in the number of students involved in the programme since then. The programme has been implemented in the classes from $1^{\text {st }}$ to $4^{\text {th }}$ grade of primary schools in all counties of the Republic of Croatia. The recent data show that 546 classes were involved in the project in the school year 2019/2020 (HŠsS, 2021).

The aims of the programme defined by Škegro et al. (2007) are as follows: encouraging the multifaceted psychosomatic development of children, building the culture of preserving and improving personal health, acquiring a habit of regular daily exercise and developing motor and functional abilities. The following objectives have been pointed out: enabling that children gain experience by movement, encouraging the acquisition of knowledge about different sports and the benefits of taking up sports, and motivating a positive attitude towards a healthy lifestyle and a healthy diet.

Sports selection is the process of selecting gifted and talented individuals who could achieve top competitive results in the future. It is necessary that children find the appropriate sports activity offering them the greatest chances of success (Milanović, 2013). Sports talents are identified and they develop in course of a continuous selection of children in universal, oriented and primary sports schools; in this context the project is regarded as a system for making a selection and directing potential young athletes in accordance with the biological, psychological and social elements (Milanović, 2013) constituting particular sports disciplines. 
THEORETICAL AND PRACTICAL PROBLEMS AND DISCUSSIONS

TEORIJSKI I PRAKTIČNI PROBLEMI I RASPRAVE

\section{The Universal Sports School Teachers}

The USŠ programme can only be carried out by persons who meet the criteria and are qualified to work with children within extracurricular school sports activities pursuant to Art 60, para. 3 of the Sports Act: "Professional work in sports ... can be done by persons with adequate professional qualifications on the level of university study programmes who also meet the conditions for a teacher of physical and health education in accordance with a special provision" (HŠSS, 2021).

There are concerns about a number of issues that have not changed over the decades. These are related to insufficient number of hours of physical education planned by the curriculum, obviously inferior status of PE: as a school subject, poor competency of the teachers and/or level of PE teachers' education (especially in lower grades of primary school) (Hardman, 2008). The results of a study conducted by Hardman (2008) show the importance of the implementation of USŠ in primary schools. Prior to the introduction of the USŠ programme in lower grades of primary school education PE was taught exclusively by primary school teachers or masters of primary education. They, however, do not have as much professional knowledge of the subject as kinesiologists, who acquired their knowledge in course of their university education. This certainly facilitates them to carry out the programme professionally. However, there are problems arising from the fact that USŠ has not been implemented in all grades, but only partially at the lower level of primary education, so that through USŠ the kinesiologists may become more involved in lower level of primary education as the project progresses.

\section{Selection in sports}

Selection in sports is a process of selecting gifted individuals who could achieve top competitive results in the future. It is essential for every child to find an adequate sports activity in which it has the greatest chances of success (Milanović, 2013). The efficient outcomes of sports preparation process depends much on an appropriate selection of individuals, i.e. those who have the abilities and predispositions for achieving excellent competitive results in a particular sport (Milanović, 2013).

Nowadays, there are a large number of those who do sports, which is a positive indicator, but as regards the highest level of sports results, there are only few, who can make the step forward. Sports selection and elements constituting sports selection should be the major functional parts within the sports system. By relying on outstanding individuals who succeed in sports through natural selection, the system loses potential top athletes. Although individuals succeed in different ways, there has been a record of positive examples of natural selection. Nevertheless, the system should not rely on individuals, but it should be governed and organised in a way that promotes sporting activities with an increasing number of professionally mentored athletes, and gives young people the opportunity to achieve their optimal results in sports. In sports, it is important to find the most talented individuals, at an early age, so that their progress can be continuously monitored and that based on a scientifically tailored exercise programme, their abilities can rise to a potential level (Horvatek, 2019). Elite young athletes count as highly selected groups. Selection is made primarily based on the basic motor and functional abilities required by a particular sport. Height and physical predispositions can be additional selection factors in some sports. For example, height is an advantage in some sports (handball, basketball), but it can also be a limiting factor in others (gymnastics) (Malina and Bouchard, 1991).

The completed higher education enables the teachers to apply their theoretical and practical knowledge in order to carry out sports selection procedures professionally because it includes a large number of factors enabling quality selection implementation. According to Milanović (2013) the requirements for both a child and the instructor/teacher, a kinesiologists, 
are that a child has the abilities and individual features highly influenced by its genetics that can be affected by training and that a child is interested in and ready for a systematic and demanding process of long-term sports preparation. The factors playing a significant role in the selection as stated by Bompa (2009) are primarily health as an absolute necessity of every person involved in sports, followed by biometric qualities or anthropometric features of an individual that are crucial for certain sports and finally genetics i.e. heritage, which plays a major role in training.

\section{Natural and sports selection}

Positively selected children are directed to top sports at first hand. "Children with a positive prediction tendency can be included in top sports upon a development monitoring period" (Milanović, 2013, 144). Children who undergo natural selection usually give up sports; they neither develop to their full potential nor acquire the habit of engaging in physical activity.

Milanović (2013) points out that we should also focus on children who have not achieved a positive prediction for playing top sports. The selectors should direct them to sports of a non-selective character in which they will satisfy their needs for playing and movement, and in their free time to carry out various physical and sporting activities in order to improve the quality of their lives (Figure 1.). If young people are left to natural selection, sports talents will be ruined. Thus, it will neither be possible to systematically bring their potential and their abilities to the optimal level, nor to influence their development so as to identify with sports, and most importantly, it will not be possible to raise their awareness of the importance of exercising to live a more functional and quality life.

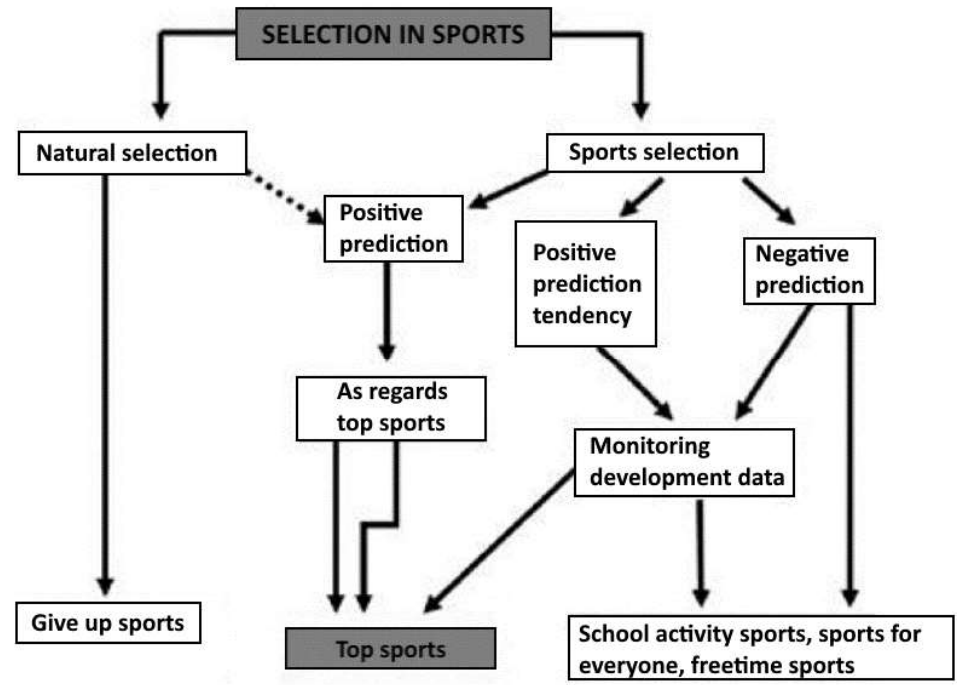

Figure 1. The sports selection procedure - a multiple activity with data on continuous monitoring of the children's/future athletes' development

\section{Early sports specialization}

Sports specialization is defined as an intensive year-round training in one sport, to the exclusion of all other sports (Jayanthi et al., 2011). Early sports specialization, as Malina (2010) 
points it out, does not bring the desired results and he presents the results of seven year monitoring of German athletes in seven types of Olympic sports. The results show that only 15 athletes out of $4,972(0.3 \%)$, who participated in the early sports specialization, achieved high level results, i.e. that they ranked among 10 best international senior athletes. A three-year follow-up recorded that 192 out of 11,287 athletes in elite sports schools (1.7\%) won a medal at an international championship.

Eastern Europe advocated early sports specialization and in sports selection focused on selecting a sport at an early age. Malina (2010) states that only $0.14 \%$ of 35,000 highly qualified Russian athletes who train in sports schools, including 2,700 candidates from selected schools, have succeeded, from initial selection to high-level sports achievement. Malina (2010) notes the observations of the German national athletes in Olympic sports relate with an early specialization. There were 1558 athletes participating in the study; successful athletes participated in multiple sports either prior to or in course with their current sport activity (juniors $2.2 \pm 1.4$; top athletes $2.4 \pm 1.6$ ). Approximately $64 \%$ of international finalists and $53 \%$ of less successful top athletes participated in other sports. Internationally successful athletes continued to do trainings in other sports until later in their lives. Thus, it has been recorded how successful athletes later began specializing in primary sports.

Myer et al. (2015) note that the lack of diverse physical activities may not allow young athletes to develop appropriate neuromuscular skills that are effective in injury prevention and do not allow the body the necessary rest from repeated activation of the same segments in their bodies. The published articles (Malina, 2010 and Myer et al., 2015) show that early specialization in sports does not give the desired results and can be counterproductive causing injuries to young athletes who prematurely opt for one sport. There are benefits in the development of children who participate in several types of sports activities, the benefits they gain from engaging in various sports are important in the prevention of injuries as well as in the development of abilities for future specialization. The persons in charge of programme implementation should be careful with the early specialization of potential candidates for top sport. The above research results indicate to the importance of USŠ in upbringing and education of young people. The USŠ programme is established in a large number of sports branches and it provides children with optimal development tailored to their potential achievements.

\section{Significance of the Universal Sports School in sports selection}

The system of directing is a process of selection, i.e. selection of children in general for sports, which provides a massive base of potential candidates for achieving top level sports results (Milanović, 2013). Škegro et al. (2007) state that the programme is not aimed at creating top athletes, but at encouraging the optimal development of motor skills potentials in children aged 6 to 10 years. However, it should be pointed out that the USŠ can be the basis for the creation of future top athletes. Within the USŠ programme, children take up many sports and types of physical activities important for their physical development and, as a result, for improving the health of the population. The programme aims at developing a culture of health and creating a habit of taking regular exercises. The activities, plans and programme of USŠ affect the development of children's (as programme participants) skills by applying knowledge and experience aimed at the optimal development of children by a group-guided approach and individualization within the group. The effective guidance system in sports and orientation towards a group of sports branches significantly determines the quality of the selection system enabling a reliable detection of gifted individuals, i.e. potential top athletes for a particular sport (Milanović, 2013). As USŠ detects the basis of young athletes, there are more and more participants in the project itself. Theoretically, it has made a good link with the selection in sports. With their expert knowledge, the kinesiologists implementing the programme have the opportunity to identify those individuals, who show potential for achieving top results in a 
particular sport, but also to encourage and create a healthy habit of doing a physical activity for children who do not show potential for top sports. In addition, the programme should monitor their development and progress, identify a possible tendency towards a positive future performance results for top sports. The USŠ practices are not directly related to selection, but to involving as many young people as possible in sporting activities and to improving the development of children. In Croatia, there has been an increase in privately owned USŠ that are better connected with sports selection and creation of top athletes. The partners of privately owned USŠ are clubs in which senior sports take place at the top level and they thus direct their students with a positive prediction to top sports in sports where, through further professional activity, their potential is lead to optimal levels for those sports disciplines in which they show a potential.

\section{CONCLUSION}

The USŠ makes it possible to implement the selection of potential athletes in Croatia, which should be further developed in order to achieve the possibility of implementing a quality and professional selection. Universal sports school within the framework of upbringing and education in primary schools throughout Croatia has made a far-reaching impact on the cognitive, conative and emotional development of children. Progressively over the years, there has been an increase in the number of young people involved in the programme, but the current focus is primarily not on the selection of children in sports. Extracurricular institutions in cooperation with sports associations make, as part of their business, the selection of young athletes, as well. In these institutions, the focus is mainly on a massive approach, maintaining and improving health, creating sports and exercising habits. The USŠ system in Croatia has been making great progress so far and there has been an increase in the number of children participating; it has been certainly looking forward to what is yet to come since its further professional activities make it a more serious part of youth sports education in Croatia year by year. It should be set as an educational system rule that PE classes are taught only by professionally qualified persons meeting the criteria for working with children. With its plan and programme, USŠ does various sports and exercise activities, so that there is no premature sports specialization, i.e. engaging in one sport through the annual training cycle. The well-being in the development of children who participate in several types of sports activities is important in injury prevention and guidance for future specialization in sports disciplines as well as the discovery of talents for playing top sports.

\section{REFERENCES}

Bompa, T. O. (2009). Periodizacija - teorija i metodologija treninga. Zagreb: Gopal.

Hardman, K. (2008). Physical education in schools: a global perspective. Kinesiology 40(1), 5-28.

Horvatek, M. (2019). Selekcija djece u tenisu i senzitivne faze razvoja motoričkih sposobnosti (Diplomski rad). Zagreb: Kineziološki fakultet u Zagrebu.

HŠSS (2021). Univerzalna Sportska Škola. Retrieved 01/02/2021 from https://skolski-sport.hr/uss

Jayanthi N. A, Pinkham C., Durazo-Arivu R., Dugas, L. \& Luke, A. (2011). The risks of sports specialization and rapid growth in young athletes. Clinical Journal of Sports Medicine. 21(2), 157.

Malina, R. M. (2010). Early sport specialization: roots, effectivness, risk. Current Sport Medicine Reports, 9(6), 364-371.

Malina, R. M. \& Bouchard, C. (1991). Growth, Maturation, and physical activity. Champaing, Illinois: Human Kinetics Books.

Milanović, D. (2013). Teorija treninga. Zagreb: Kineziološki fakultet u Zagrebu. 
THEORETICAL AND PRACTICAL PROBLEMS AND DISCUSSIONS

TEORIJSKI I PRAKTIČNI PROBLEMI I RASPRAVE

Myer G. D., Jayanthi N., Difiori J. D., Faigenbaum A. D., Kiefer A. W., Logerstedt D. \& Micheli L.J. (2015). Sports Does Early Sports Specialization Increase Negative Outcomes and Reduce the Opportunity for Success in Young Athletes? Sports Health, 7(5), 437-442.

Škegro D., Dujić I., Čustonja H. \& Košutić J. (2007). Plan i program rada univerzalne športske škole. Zagreb: Hrvatski školski sportski savez. Retrieved 01/02/2021 from https://skolski-sport-zg.hr/ dokumenti/778-Plan_i_program_rada_US\%C5\%A0.pdf 